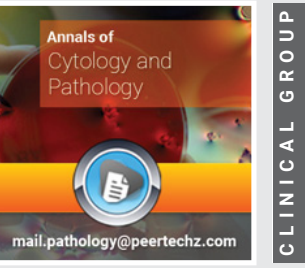

\title{
Development of a management guidewheel for vulvar cancer
}

\author{
Mahmoud Samy Ismail1-3*, Fouad Ismail ${ }^{4}$, Julia Ismail ${ }^{5}$, Muneera \\ AlKhalifa ${ }^{6}$, Rehab Ismael', Reham Fathi', Wassan AI Ani', Shaikha AI \\ Hajri ${ }^{1}$, Mariam Fida ${ }^{2}$, Alaa Zeineldine ${ }^{7}$ and Uwe Torsten ${ }^{3,8}$ \\ ${ }^{1}$ Department of Obstetrics and Gynecology, King Hamad University Hospital (KHUH), Kingdom of \\ Bahrain \\ ${ }^{2}$ Bahrain Oncology Centre (BOC), Kingdom of Bahrain \\ ${ }^{3}$ Department of Gyne-Oncology, Charitè University Hospital, Humboldt University, Berlin, Germany \\ ${ }^{4}$ University of Applied Arts, Vienna, Austria \\ ${ }^{5}$ Vienna University of Technology, Vienna, Austria \\ ${ }^{6}$ King Hamad University Hospital (KHUH), Kingdom of Bahrain \\ ${ }^{7}$ Department of Obstetrics and Gynecology, AlMana General Hospital, AlKhobar, Saudi Arabia \\ ${ }^{8}$ Department of Obstetrics and Gynecology, Royal College of Surgeons in Ireland (RCSI), Kingdom of \\ Bahrain
}

Received: 29 December, 2021

Accepted: 18 January, 2022

Published: 19 January, 2022

*Corresponding author: Mahmoud Samy Ismail, Professor, Department of Obstetrics and Gynecology, King Hamad University Hospital, Building 2435, Road 2835, Block 228, Busaiteen P.O Box 24343, Al Muharraq, Kingdom of Bahrain, E-mail: samyismael@hotmail.com

Copyright: (c) 2022 Ismail MS, et al. This is an openaccess article distributed under the terms of the Creative Commons Attribution License, which permits unrestricted use, distribution, and reproduction in any medium, provided the original author and source are credited.

Keywords: Vulvar cancer; Surgical staging; Radiotherapy; Chemotherapy; Systemic therapy; FIGO classification; Guidelines; Persistent or recurrent disease; Therapy for relapse; Surveillance; Surgical node status; Radical hysterectomy; Adenopathy; Distant metastases

https://www.peertechzpublications.com

\section{Check for updates}

\section{Abstract \\ Ismail's Cancer Vulva Management Guidewheel is designed to enable physicians to refer to a quick and comprehensive reference to recommendations on the management of vulvar cancer at various stages. The wheel consists of patient characteristics, including the FIGO stage and the possible treatment modalities available along with alternatives. We compared guidelines on the management of vulvar cancer by international health organizations including the National Comprehensive Cancer Network (NCCN), the Society of Gynecologic Oncology (SGO), the European Society of Gynaecological Oncology (ESGO), the European Society of Urogenital Radiology (ESUR), the British Gynaecological Cancer Society (BGCS), the Royal College of Obstetricians and Gynaecologists (RCOG), the Japanese Society of Gynecologic Oncology (JSGO), the Society of Obstetricians and Gynaecologists of Canada (SOGC) and the International Federation of Gynecology and Obstetrics (FIGO). Their respective recommendations have been compared and carefully integrated on the guidewheel.}

\section{Abbreviations}

BGCS: British Gynaecological Cancer Society; CT: Computed Tomography; EBRT: External Beam Radiotherapy; ESGO: European Society of Gynaecological Oncology; ESUR: European Society of Urogenital Radiology; FIGO: International Federation of Gynecology and Obstetrics; FNA: Fine-Needle Aspiration; JSGO: Japanese Society of Gynecologic Oncology; LN: Lymph Node; LND: Lymph Node Dissection; MRI: Magnetic Resonance Imaging; NCCN: National Comprehensive Cancer Network; PET: Positron Emission Tomography; RCOG: Royal College of Obstetricians and Gynaecologists; SGO: Society of Gynecologic Oncology; SLN: Sentinel Lymph Node; SOGC: Society of Obstetricians and Gynaecologists of Canada; TNM: Tumors, Nodes, and Metastases; VC: Vulvar Cancer.

\section{Introduction}

Vulvar Cancer (VC) is the fourth most common gynecologic cancer as it constitutes $2-5 \%$ of all gynecologic cancers [17]. Early-stage VC with no nodal involvement generally has a good prognosis with a 5-year survival of more than $80 \%$ compared to a 5 -year survival of less than $50 \%$ in patients with Lymph Node (LN) involvement [5-9]. Risk factors associated with developing VC include increasing age, smoking, immunodeficiency, and chronic skin diseases, such as lichen sclerosus $[6,9]$. The treatment of VC involves surgery, Radiotherapy (RT) and chemotherapy [2-4,6,8,9]. There are no screening tests proven to be effective for VC $[1,2,8]$.

Different health organizations worldwide have developed 
guidelines regarding the management of VC. We reviewed and compared guidelines by the following organizations: the National Comprehensive Cancer Network (NCCN), the Society of Gynecologic Oncology (SGO), the European Society of Gynaecological Oncology (ESGO), the European Society of Urogenital Radiology (ESUR), the British Gynaecological Cancer Society (BGCS), the Royal College of Obstetricians and Gynaecologists (RCOG), the Japanese Society of Gynecologic Oncology (JSGO), the Society of Obstetricians and Gynaecologists of Canada (SOGC) and the International Federation of Gynecology and Obstetrics (FIGO) $[1-8,10]$. Since the guidelines by NCCN are the most frequently updated, the guidewheel mainly reflects their recommendations [6]. We are also comparing those guidelines in another review article to emphasize the similarities and differences in those recommendations.

Ismail's Cancer Vulva Management Guidewheel is intended to help serve healthcare professionals in finding a quick resource to refer to recommendations on managing patients with VC. This can help in rapid decision-making and aid in counseling patients regarding the available options of treatment appropriate for their cases. It is not meant to replace recommendations and algorithms set in place by those international guidelines. We have designed a similar guidewheel for managing abnormal pap smears, uterine neoplasms, and cervical cancer, which is soon to be published [11,12]. We also published several chapters on managing abnormal pap smears and cervical cancer screening in a book entitled "Applied Colposcopy and Cytology" [13-16].

\section{About this wheel}

We designed Ismail's Cancer Vulva Management Guidewheel to reflect the current recommendations from various guidelines regarding the management of VC. It is comprised of a base (Figure 1) and an inner wheel (Figure 2). When fully assembled, the inner wheel is placed on the base and can be rotated to display the treatment modality, on the inner wheel, recommended for a particular classification of VC, on the outer rim of the guidewheel (Figure 3). The back of the guidewheel's base shows how to use the guidewheel, its components and the FIGO staging of VC (Figure 4).

The inner wheel demonstrates eleven possible options to manage patients with $\mathrm{VC}$ as follows:

- Primary Therapy: a. Surgery; b. Radiotherapy; c. Chemotherapy; d. Systemic

- Surgical Therapy: a. Resection (A. Wide, B. Radical, C. Unilateral, D. Bilateral); b. Vulvectomy (A. Partial, B. Total, C. Radical); c. LN Dissection (A. Sentinel LN (SLN)); d. Re-excision

- Additional Work-Up: a. Imaging; b. Pathology (A. Biopsy, B. Fine Needle Aspiration (FNA))

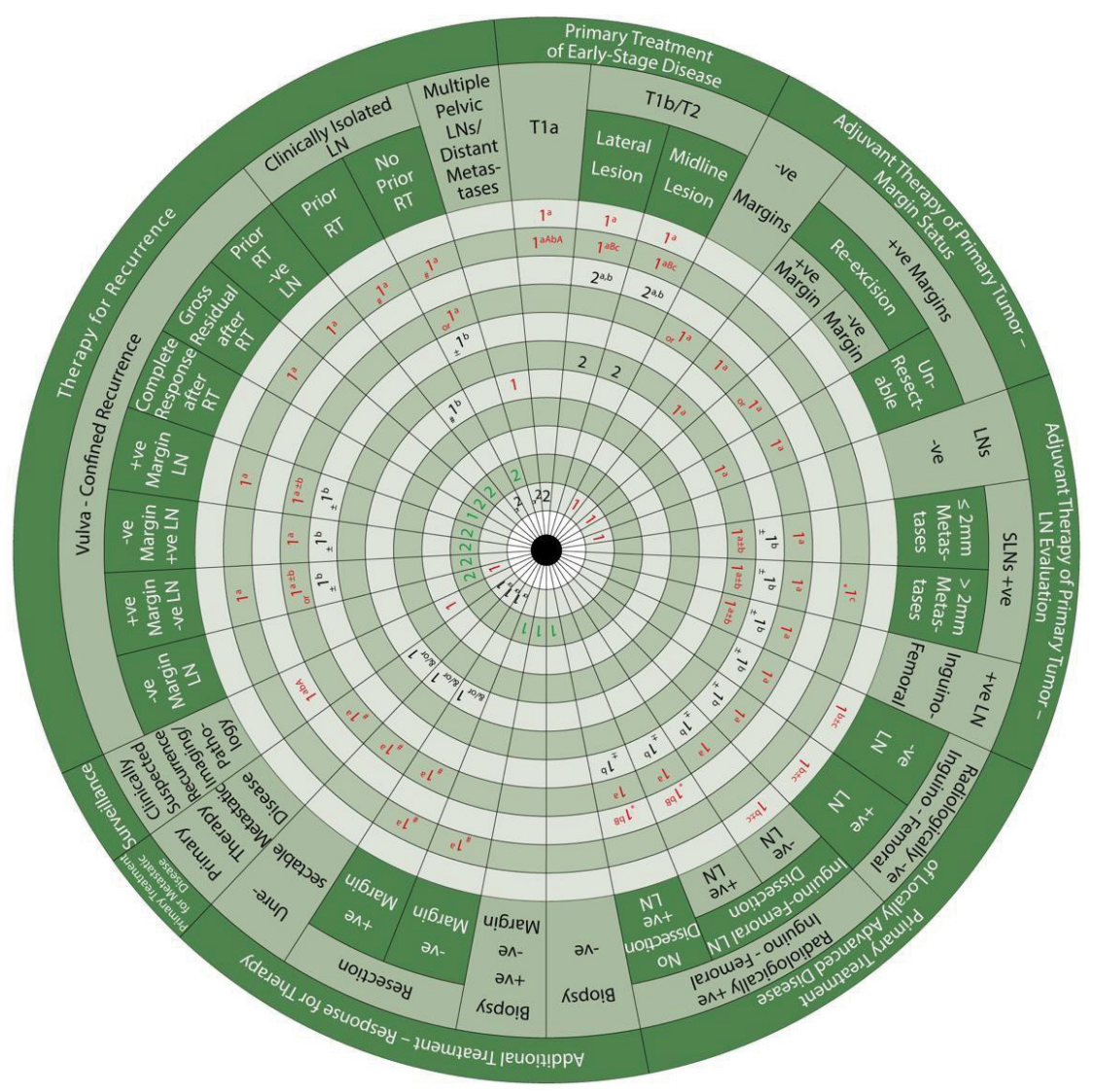

Figure 1: The base of Ismail's Cancer Vulva Management Guidewheel demonstrates the stages of vulvar cancer and the color-coded treatment modalities.

Citation: Ismail MS, Ismail F, Ismail J, AIKhalifa M, Ismael R, et al. (2022) Development of a management guidewheel for vulvar cancer. Ann Cytol Pathol 7(1): 001-013. DOI: https://dx.doi.org/10.17352/acp.000024 


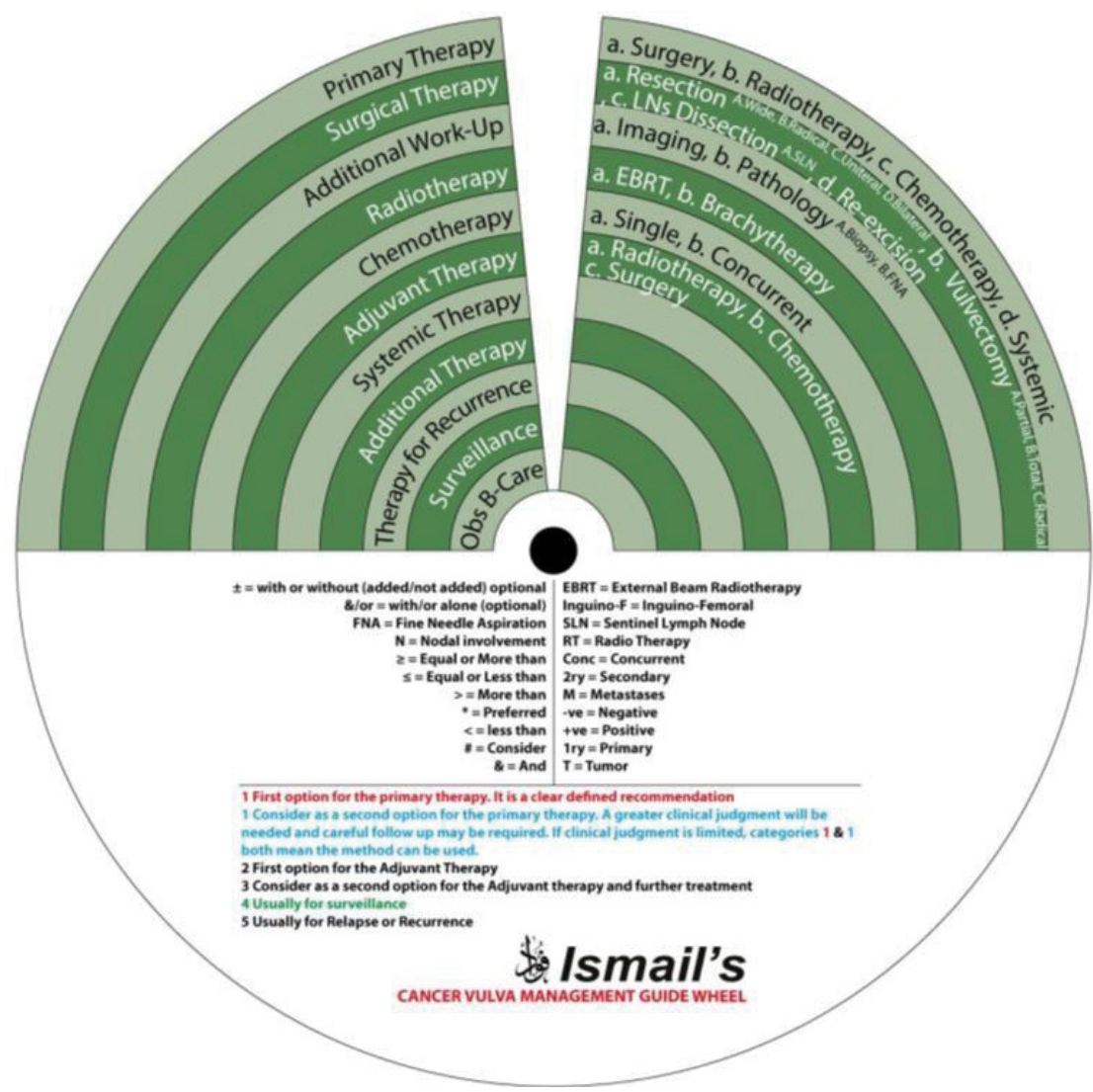

Figure 2: The inner wheel of the guidewheel that is placed on top of the base demonstrates the various treatment modalities and the available options for each.

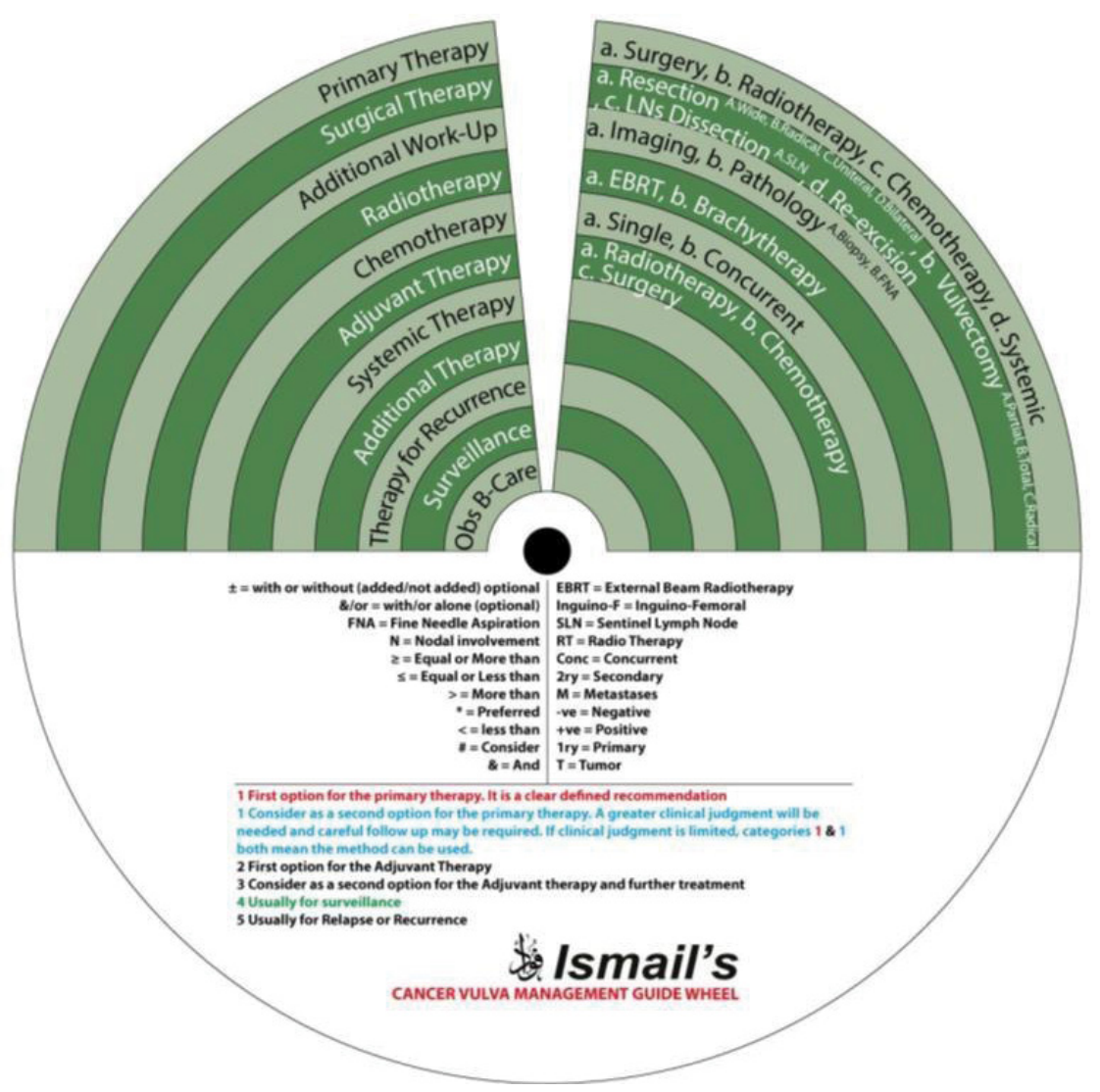

Figure 3: The guidewheel fully assembled demonstrating the management of a patient with Stage T1a vulvar cancer.

Citation: Ismail MS, Ismail F, Ismail J, AIKhalifa M, Ismael R, et al. (2022) Development of a management guidewheel for vulvar cancer. Ann Cytol Pathol 7(1): 001-013. DOI: https://dx.doi.org/10.17352/acp.000024 


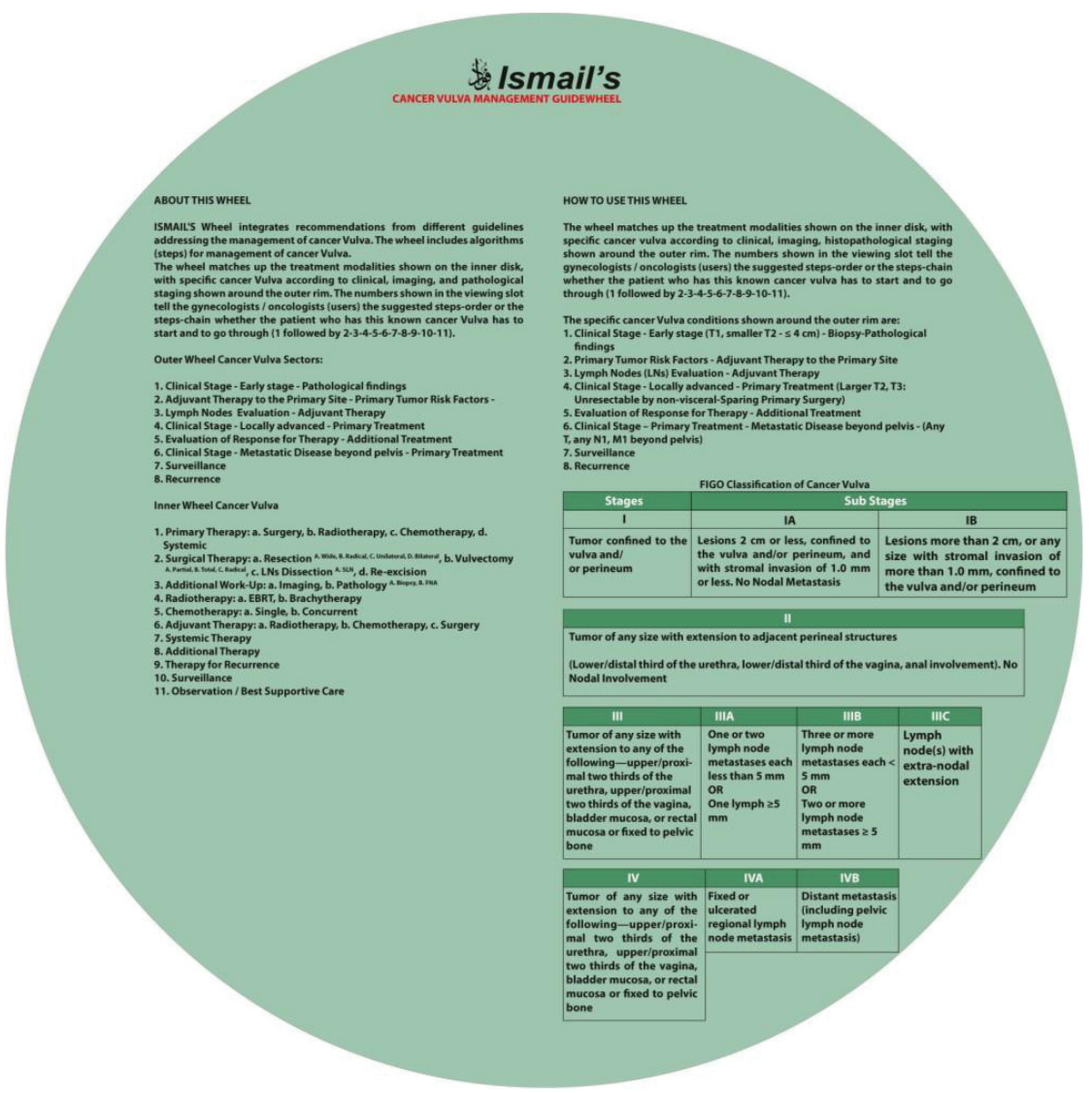

Figure 4: The back of the guidewheel describes how to use the guidewheel in addition to the FIGO staging system of vulvar cancer

- Radiotherapy: a. External Beam Radiotherapy (EBRT); b. Brachytherapy (BT)

- Chemotherapy: a. Single; b. Concurrent

- Adjuvant Therapy: a. Radiotherapy; b. Chemotherapy; c. Surgery

- Systemic Therapy

- Additional Therapy

- Therapy for Recurrence

- Surveillance

- Observation / Best Supportive Care

\section{How to use the guidewheel}

When using the guidewheel, rotating the inner wheel along the base helps align the treatment modalities with the stage of VC. The resulting viewing slot demonstrates the recommended steps of management in chronological order, see Figure 3. Please note that all recommendations are Class IIA unless otherwise specified. The base of the guidewheel displays colorcoded treatment modalities in order. The numbers signify the steps and alternative options as follows:

$1 \rightarrow$ This marks the first step for primary therapy. It is a clearly defined recommendation.
$1 \rightarrow$ This is another option for the first step of primary therapy. It might require greater clinical judgment and careful follow-up. If clinical judgment is limited, either the option in red or blue could be used.

$2 \rightarrow$ This marks the second step which could mean adjuvant therapy, further treatment, surveillance or treatment for recurrence.

Abbreviations used on the wheel include the following:

\begin{tabular}{|l|l|l|l|}
\hline \pm & $\begin{array}{l}\text { There is an option to } \\
\text { add or to not add } \\
\text { (with or without) }\end{array}$ & Inguino-F & Fine Needle Aspiration \\
\hline$>$ & More than & Inguinofemoral \\
\hline$<$ & Less than & M & Nodal involvement \\
\hline$\geq$ & Equal or more than & T & Metastases \\
\hline$\leq$ & Equal or less than & RT & Radiotherapy \\
\hline$\#$ & Consider & SLN & Sentinel Lymph Node \\
\hline$*$ & Preferred & EBRT & $\begin{array}{l}\text { External Beam } \\
\text { Radiotherapy }\end{array}$ \\
\hline$\&$ & And & 1ry & Primary \\
\hline \&/or & $\begin{array}{l}\text { And/or alone } \\
\text { (optional) }\end{array}$ & 2ry & Secondary \\
\hline +ve & Positive & Conc & Concurrent \\
\hline -ve & Negative & Obs, B-C & Observation, Best Care \\
\hline
\end{tabular}

The sectors regarding the management of vulvar cancer are shown on the outer rim of the guidewheel's base as follows: 
1. Primary Treatment of Early-Stage Disease (T1a, T1b and smaller T2)

2. Adjuvant Therapy to Primary Tumor based on Margin Status

3. Adjuvant Therapy to Primary Tumor Based on Lymph Node Evaluation

4. Primary Treatment of Locally Advanced Disease

5. Additional Treatment Based on Response to Therapy

6. Primary Treatment for Metastatic Disease

7. Surveillance

\section{Therapy for Recurrence}

The FIGO 2017 classification of VC is displayed on the back of the wheel (Figure 4) and is listed as follows [2]:

\section{Stages and Sub-Classification}

Stage I: Tumor confined to the vulva

IA: Lesions $\leq 2 \mathrm{~cm}$ in size, confined to the vulva or perineum and with stromal invasion $\leq 1 \mathrm{~mm}^{3}$, no nodal metastasis

Stage II: Tumor of any size with extension to adjacent perineal structures (lower third of urethra, lower third of vagina, anus) with negative nodes

Stage III: Tumor of any size with or without extension to adjacent perineal structures

(lower third of urethra, lower third of vagina, anus) with positive inguinofemoral nodes

IIIA: With 1 lymph node metastasis $(\geq 5 \mathrm{~mm})$ OR

With 1-2 lymph node metastasis(es) $(<5 \mathrm{~mm})$

IIIB: With $2 \leq$ lymph node metastases $(\geq 5 \mathrm{~mm})$ OR

With $3 \leq$ lymph node metastases $(<5 \mathrm{~mm})$

IIIC: With positive nodes with extracapsular spread

Stage IV: Tumor invades other regional (upper $2 / 3$ urethra, upper $2 / 3$ vagina) or distant structures

IVA: Tumor invades any of the following:

Upper urethral and/or vaginal mucosa, bladder/rectal mucosa, or fixed to pelvic bone

OR

Fixed or ulcerated inguinofemoral lymph nodes

IVB: Any distant metastasis including pelvic lymph nodes

\section{Recommendations on managing patients with vulvar cancer using the Guidewheel}

Sector 1. Primary Treatment of Early-Stage Disease (T1a, T1b and smaller T2) (Figure 5).

For patients with stage T1a SCC of the vulva $\left(\leq 1 \mathrm{~mm}^{3}\right.$ invasion) (Class):

- 1a: Primary treatment is surgery (1a).

- 1aAbA: Surgical treatment (1) with wide local resection (aA) and partial vulvectomy (bA).

- 2: The second step is observation if margins are negative after surgery.
In a vulvar lesion, $\mathbf{2} \mathrm{cm}$ or more lateral to the midline at Stage $\mathrm{T} 1 \mathrm{~b}$ or $\mathrm{T} 2$ with invasion $>1 \mathrm{~mm}^{3}$ and $\leq 4 \mathrm{~cm}$ in size:

- 1a: Primary treatment is surgery (1a).

- 1aBc: Surgical treatment (1) with radical local resection (aB) or modified radical vulvectomy with ipsilateral inguinofemoral LN evaluation in the form of SLN biopsy or ipsilateral inguinofemoral dissection (c).

- 2a, b: Additional workup (2) with imaging (a) and pathology (b) is warranted.

- 2: The next step is adjuvant therapy.

In an anterior or posterior midline vulvar lesion Stage T1b or $\mathrm{T} 2$ with invasion $>1 \mathrm{~mm}^{3}$ and $\leq 4 \mathrm{~cm}$ in size:

- 1a: Primary treatment is surgery (1a).

- 1aBc: Surgical treatment (1) with radical local resection (aB) or modified radical vulvectomy with bilateral inguinofemoral LN evaluation in the form of SLN biopsy or bilateral inguinofemoral dissection (c).

- 2a, b: Additional workup (2) with imaging (a) and pathology (b) is warranted.

- 2: The next step is adjuvant therapy.

Sector 2. Adjuvant Therapy to Primary Tumor based on Margin Status (Figure 6)

If margins are negative for the disease

- 1: Adjuvant therapy to the primary tumor is either observation (1)

- or 1a: An alternative is radiotherapy with EBRT (1a) if there are positive risk factors. Such risk factors include lymphovascular space invasion, tumor size, depth of invasion close tumor margins measuring less than 8 $\mathrm{mm}$ and pattern of invasion [6].

If margins were initially positive for the disease and then negative after re-excision, the same management as for negative margins apply:

- 1: Adjuvant therapy to the primary tumor is either observation (1)

- or 1a: An alternative is radiotherapy with EBRT (1a) if there are positive risk factors (as mentioned above).

If margins are positive for disease even after re-excision:

- 1a: Adjuvant therapy is radiotherapy with EBRT (1a).

If a tumor has positive margins and cannot be resected without exenteration:

- 1a: Adjuvant therapy is radiotherapy with EBRT (1a).

Sector 3. Adjuvant Therapy to the Nodes based on Lymph Node Evaluation (Figure 7). 


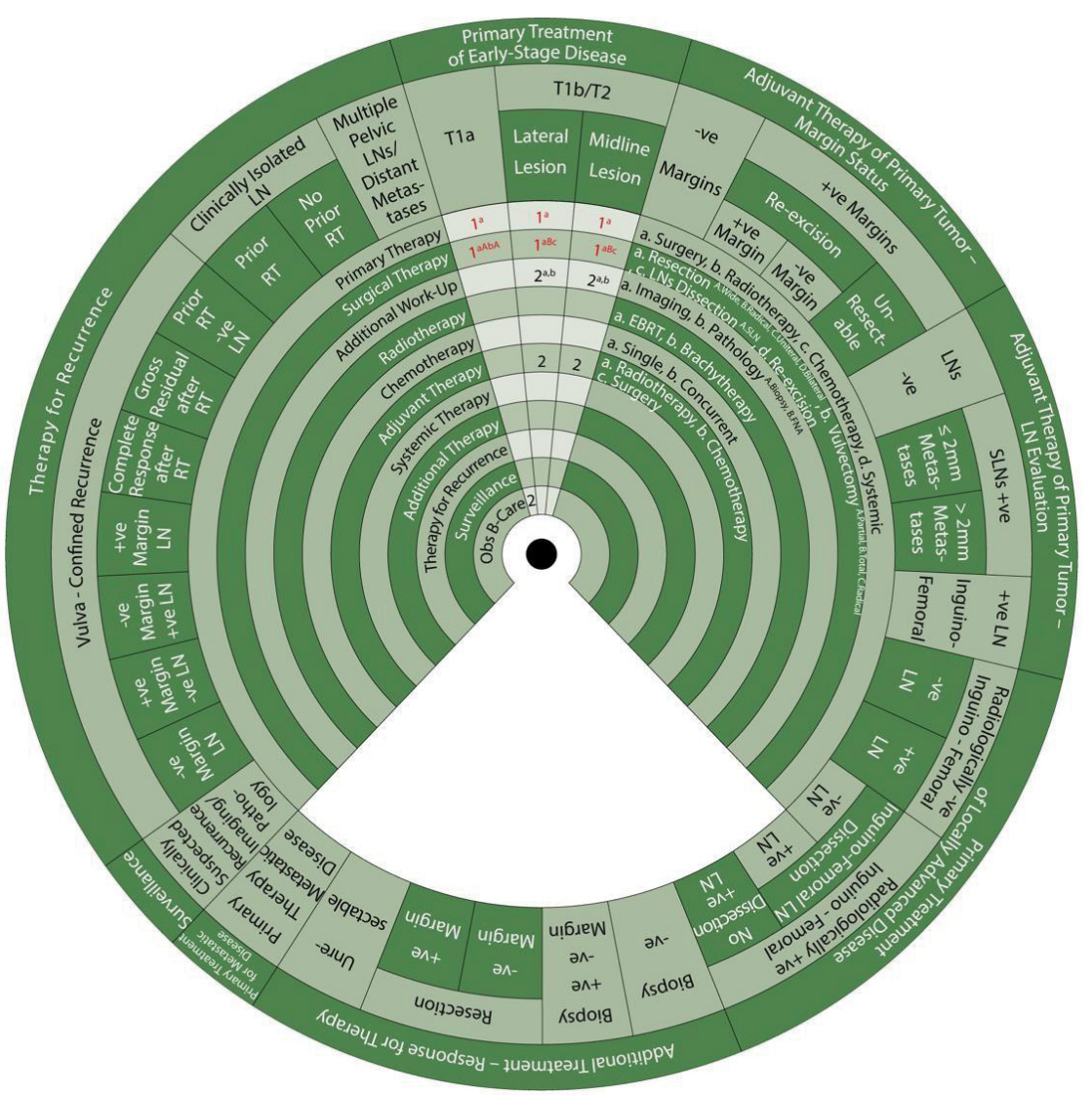

Figure 5: Management of Early-Stage Disease.

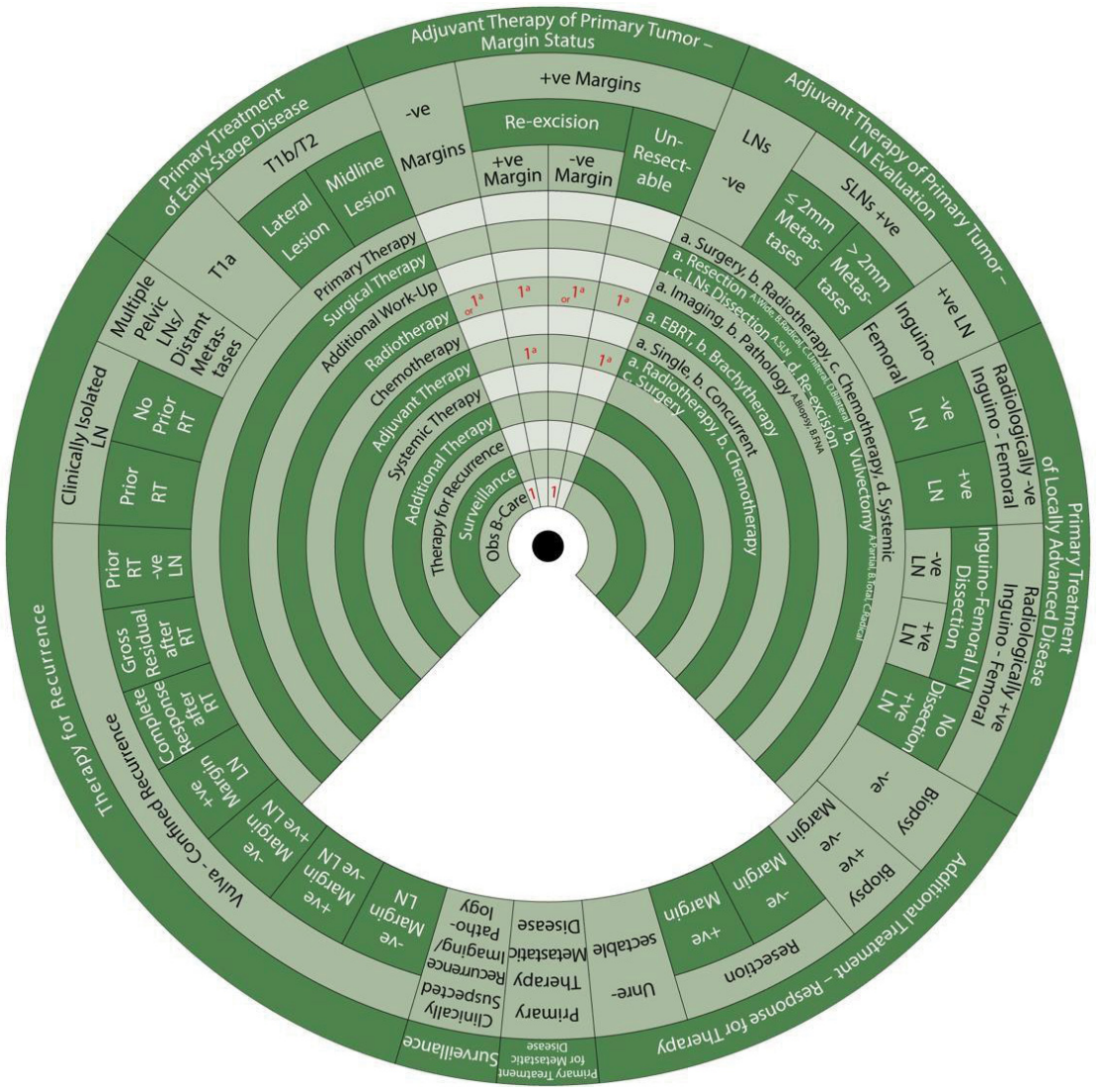

Figure 6: Adjuvant Therapy to Primary Tumor based on Margin Status.

Citation: Ismail MS, Ismail F, Ismail J, AIKhalifa M, Ismael R, et al. (2022) Development of a management guidewheel for vulvar cancer. Ann Cytol Pathol 7(1): 001-013. DOI: https://dx.doi.org/10.17352/acp.000024 


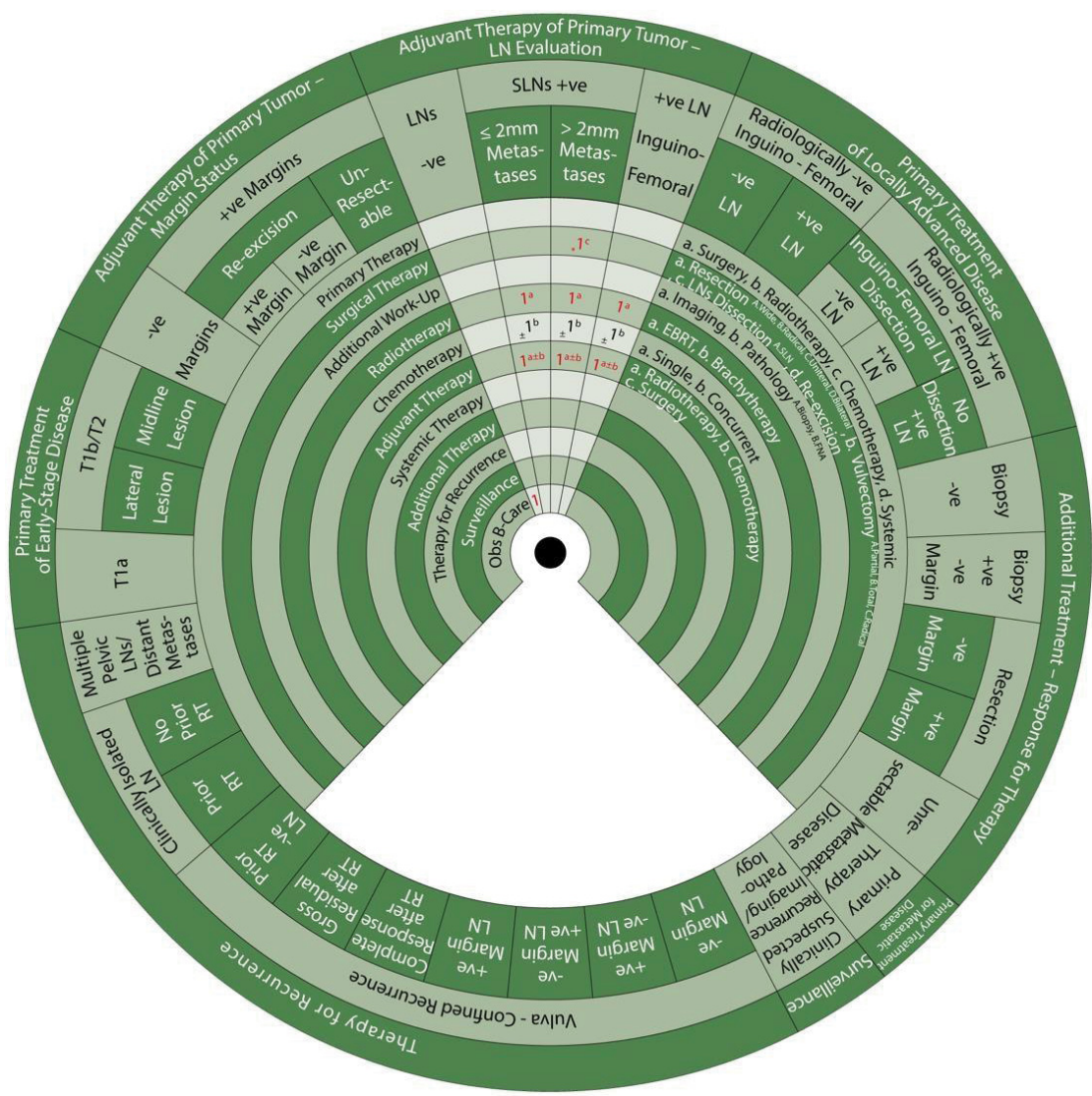

Figure 7: Adjuvant Therapy to Nodes based on Lymph Node Evaluation.

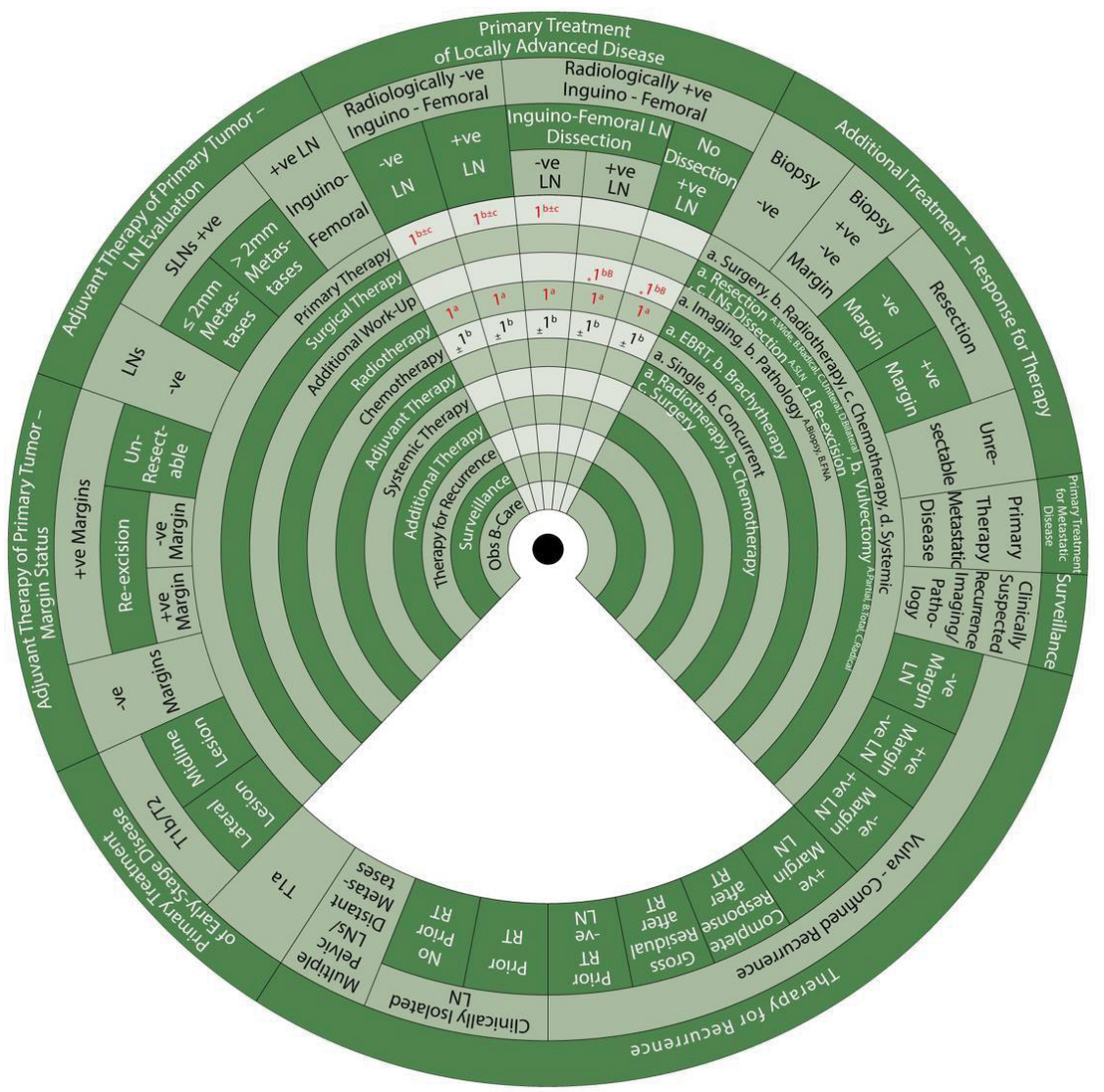

Figure 8: Primary Treatment to Locally Advanced Disease.

Citation: Ismail MS, Ismail F, Ismail J, AlKhalifa M, Ismael R, et al. (2022) Development of a management guidewheel for vulvar cancer. Ann Cytol Pathol 7(1): 001-013. DOI: https://dx.doi.org/10.17352/acp.000024 
If lymph nodes, whether SLN or inguinofemoral, are negative, adjuvant therapy to the nodes is:

- 1: Observ ation

If there are positive SLN and metastases measuring $2 \mathrm{~mm}$ or less, adjuvant therapy to the nodes is:

- $1 \mathrm{a} \pm \mathrm{b}$ : Adjuvant therapy (1) with radiotherapy (a) \pm chemotherapy (b).

- 1a: Radiotherapy with EBRT (1a) (Class I recommendation)

- \pm 1 b: With or without concurrent chemotherapy (1b).

If there are positive SLN and metastases measuring more than $2 \mathrm{~mm}$,

- *1c: The preferred $(*)$ surgical treatment is complete LN dissection (1c).

- 1a \pm b: Adjuvant therapy (1) with radiotherapy (a) \pm chemotherapy (b).

- 1a: Radiotherapy with EBRT (1a) (Class I recommendation)

- $\pm 1 b$ : With or without concurrent chemotherapy (1b).
If there are positive lymph nodes after inguinofemoral node dissection, adjuvant therapy to the nodes:

- $1 \mathrm{a} \pm \mathrm{b}$ : Adjuvant therapy (1) with radiotherapy (a) \pm chemotherapy (b).

- 1a: Radiotherapy with EBRT (1a) (Class I recommendation)

- $\pm 1 \mathrm{~b}$ : With or without concurrent chemotherapy (1b).

Sector 4. Primary Treatment to Locally Advanced Disease (Figure 8).

If there are negative inguinofemoral LNs on imaging and either negative or positive on biopsy with inguinofemoral LN dissection, or positive inguinofemoral LNs on imaging but negative following biopsy, the same management applies, as follows:

- $1 \mathrm{~b} \pm \mathrm{c}$ : Primary treatment (1) is radiotherapy (b) \pm chemotherapy (c).

- 1a: Radiotherapy with EBRT (1a)

- $\pm 1 \mathrm{~b}$ : With or without concurrent chemotherapy (1b).

If there are positive inguinofemoral LNs on imaging and/or confirmed on biopsy following inguinofemoral LN dissection or if LN dissection has not been performed:

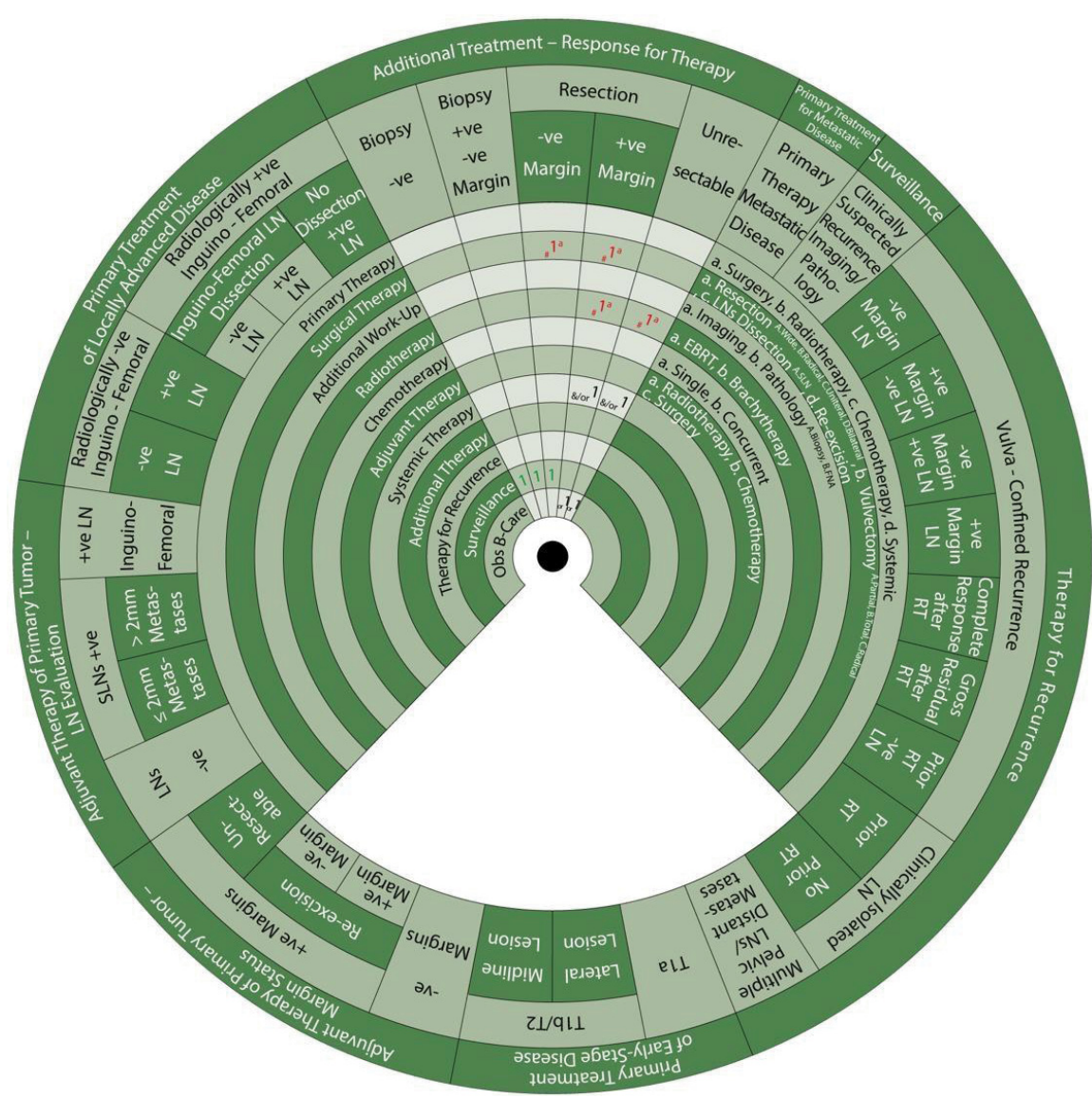

Figure 9: Additional Treatment Based on Response to Therapy.

Citation: Ismail MS, Ismail F, Ismail J, AlKhalifa M, Ismael R, et al. (2022) Development of a management guidewheel for vulvar cancer. Ann Cytol Pathol 7(1): 001-013. DOI: https://dx.doi.org/10.17352/acp.000024 
- $\quad *_{1} \mathrm{bB}$ : The preferred $(*)$ additional workup is pathology with FNA (bB).

- 1a: This is followed by radiotherapy (1) with EBRT (a)

- $\pm 1 \mathrm{~b}$ : With or without concurrent chemotherapy (1b).

Sector 5. Additional Treatment Based on Response to Therapy (Figure 9).

Additional treatment for patients who are clinically negative for the residual tumor in the primary site or nodes and those with negative biopsy is:

- 1: Surveillance (1).

For those who are either clinically positive or negative for residual tumor but positive biopsy:

- \#1a: Consider (\#) surgical resection (1a).

- 2: The next step is surveillance (2) if margins are negative after resection.

For patients who are clinically positive for residual tumor with positive margins after resection:

- \#1a: Consider (\#) surgical resection (1a) such as pelvic exenteration (if central recurrence).

- \#1a: Also consider radiotherapy with EBRT (1a)
- \&/or 1: And/or Systemic therapy alone

- Or 1: Or best supportive care

For patients who are clinically positive for the residual tumor in the primary site or nodes that is unresectable:

- \#1a: Consider radiotherapy with EBRT (1a)

- \&/or 1: And/or Systemic therapy alone

- Or 1: Or best supportive care

Sector 6. Primary Treatment for Metastatic Disease (Figure 10)

For patients with metastatic disease beyond the pelvis:

- \#1a: Consider radiotherapy with EBRT (1a)

- \&/or 1: And/or Systemic therapy alone

- Or 1: Or best supportive care

Sector 7. Surveillance (Figure 11)

- For patients with clinically suspected recurrence:

- 1abA: Additional workup (1) with imaging (a) and pathology in the form biopsy (bA) is warranted.

- 1: The next step is therapy for recurrence.

Sector 8. Therapy for Recurrence (Figure 12).

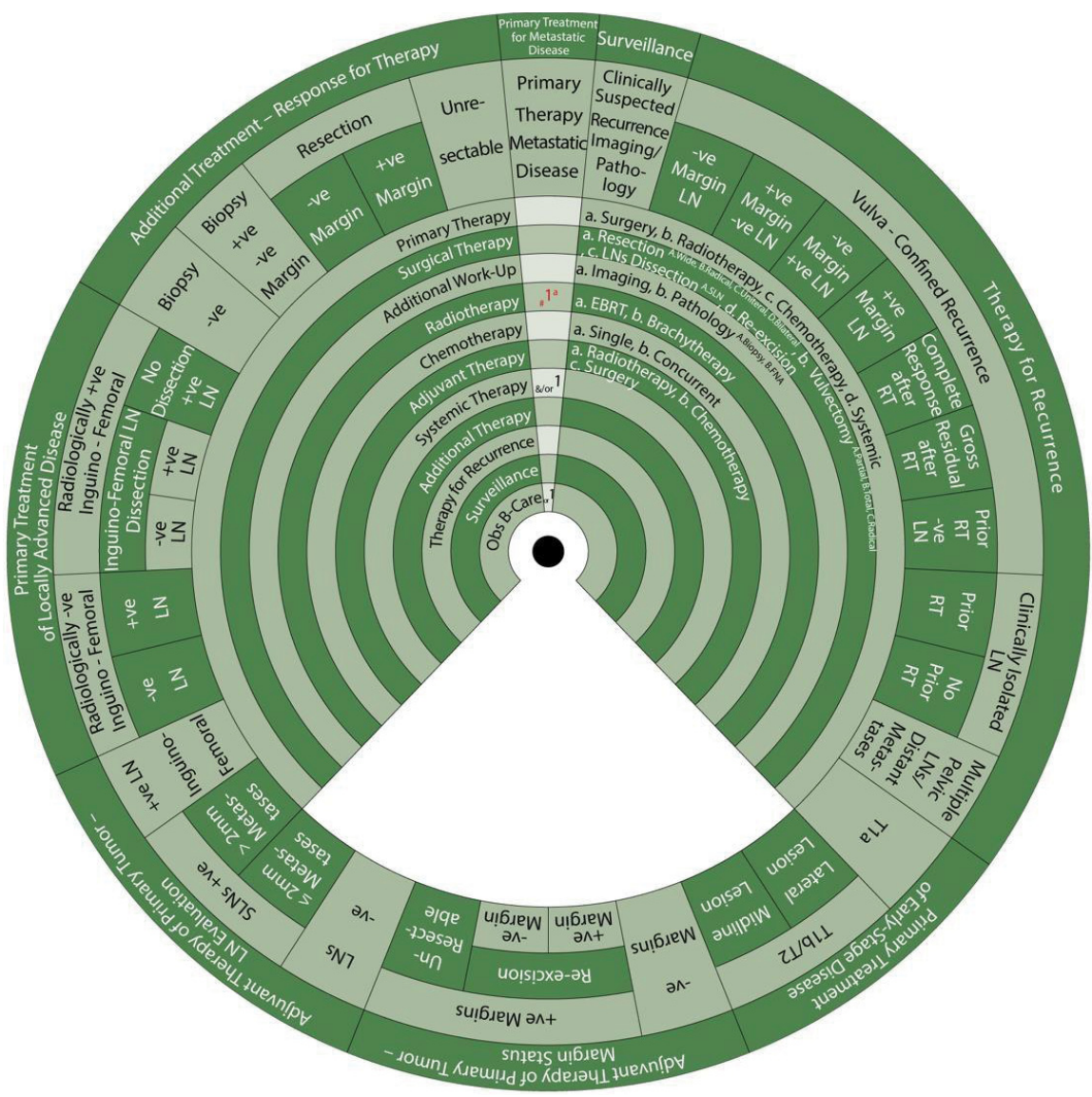

Figure 10: Primary Treatment for Metastatic Disease.

Citation: Ismail MS, Ismail F, Ismail J, AIKhalifa M, Ismael R, et al. (2022) Development of a management guidewheel for vulvar cancer. Ann Cytol Pathol 7(1): 001-013. DOI: https://dx.doi.org/10.17352/acp.000024 


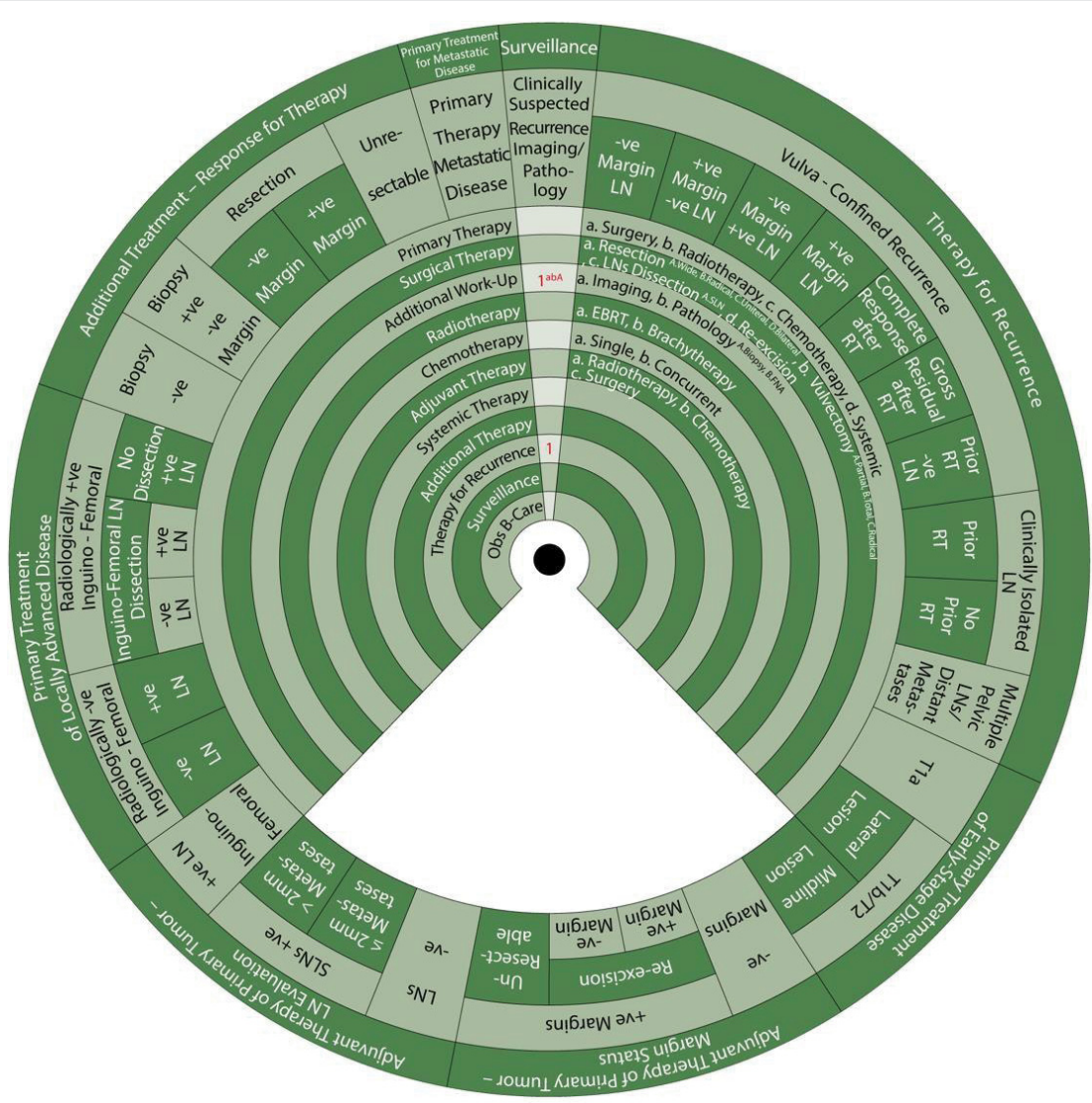

Figure 11: Surveillance.

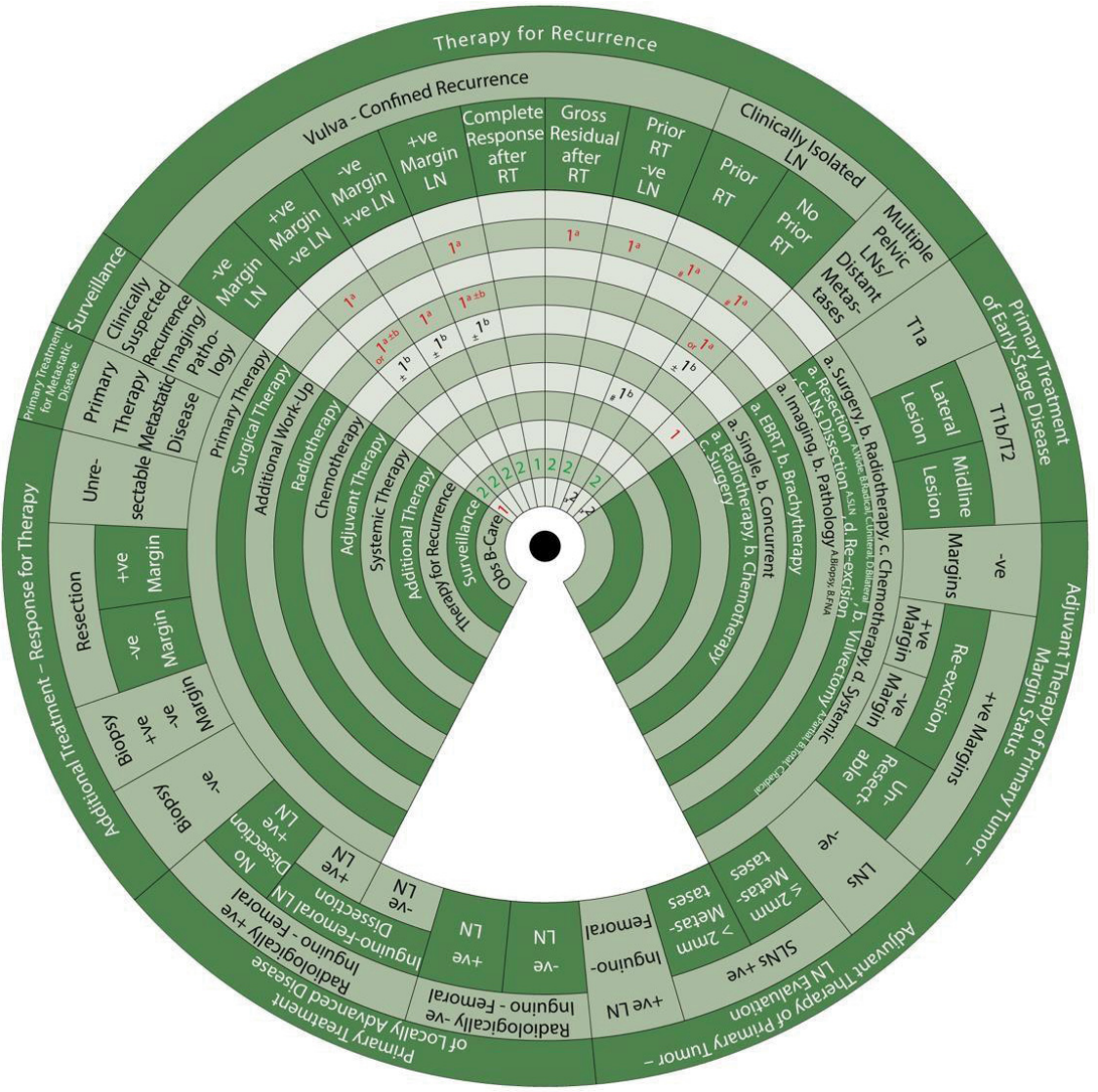

Figure 12: Therapy for Recurrence.

Citation: Ismail MS, Ismail F, Ismail J, AIKhalifa M, Ismael R, et al. (2022) Development of a management guidewheel for vulvar cancer. Ann Cytol Pathol 7(1): 001-013. DOI: https://dx.doi.org/10.17352/acp.000024 
Patients with vulva-confined recurrence and clinically negative nodes must undergo radical excision with unilateral or bilateral inguinofemoral dissection if LN dissection was not previously done. The margin and LN status post-operatively guide treatment as shown below.

For patients with vulva-confined recurrence with biopsyconfirmed negative nodes and margins and no prior RT:

- 1 : Observation is warranted.

- $\quad$ 2: This is followed by surveillance (2).

For patients with vulva-confined recurrence with positive margins, negative nodes, and no prior RT:

- 1d: The first step is a surgical treatment (1) with reexcision (d).

- Or $1 \mathrm{a} \pm \mathrm{b}$ : An alternative is a radiotherapy (1) with EBRT (a) \pm BT (b)

- $\pm 1 \mathrm{~b}$ : With or without concurrent chemotherapy (1b) (Class IIB recommendation)

- 2: The next step is surveillance (2).

For patients with vulva-confined recurrence with negative margins, positive nodes, and no prior RT:

- 1a: The first step is a radiotherapy (1) with EBRT (a).

- $\pm 1 \mathrm{~b}$ : With or without concurrent chemotherapy (1b).

- $\quad$ 2: The next step is surveillance (2).

For patients with vulva-confined recurrence with positive margins and nodes and no prior RT:

- $1 \mathrm{a} \pm \mathrm{b}$ : The first step is a radiotherapy (1) with EBRT (a) \pm BT (b).

- \pm 1 b: With or without concurrent chemotherapy (1b).

- $\pm 1 \mathrm{~d}$ : With or without surgical treatment (1) with reexcision (d).

- 2: The next step is surveillance (2).

Another option for patients with vulva-confined recurrence and clinically negative nodes with no prior RT is EBRT with or without BT with or without concurrent chemotherapy. Further management depending on the response to this treatment is described as follows.

For patients with vulva-confined recurrence with no prior RT and complete response to radiotherapy and/or chemotherapy:

\section{- $\quad$ : Surveillance (1).}

For patients with vulva-confined recurrence with no prior RT and gross residual vulvar tumor following radiotherapy and/or chemotherapy:
- 1a: The first step is a surgical treatment (1) with resection (a).

- 2: Surveillance (2).

For patients with vulva-confined recurrence with clinically negative nodes and prior RT:

- 1a: The first step is a surgical treatment (1) with resection (a).

- 2: Surveillance (2).

For patients with isolated groin/pelvic recurrence with no prior EBRT:

- \#1a: The first step is to consider (\#) surgical treatment (1) with resection (a) of positive LNs if possible.

- 1a: This is followed by radiotherapy (1) with EBRT (a)

- $\pm 1 \mathrm{~b}$ : With or without concurrent chemotherapy (1b).

- 2: Surveillance (2).

For patients with isolated groin/pelvic recurrence with prior EBRT:

- \#1a: The first step is to consider (\#) surgical treatment (1) with resection (a).

- \&/or 1b: And/or systemic chemotherapy alone

- Or 2: Otherwise, best supportive care is indicated.

For patients with distant metastasis, multiple pelvic nodes, or prior pelvic EBRT:

- 1: The first step is systemic therapy (1) (Class IIB recommendation)

- Or 2: An alternative is the best supportive care.

\section{Discussion}

Confirming the diagnosis of VC requires clinical history, examination and incisional biopsy $[1-3,6-8,10]$. Up to $90 \%$ of VC is squamous cell carcinoma, other rare types of VC may include melanoma, basal cell carcinoma, adenocarcinoma, and Bartholin's gland tumors [1-3,6-8]. VC most commonly occurs in women over the age of 65 years but can also occur in younger patients $[3,8]$. Patients may present with vulval itching, lump, or bleeding $[2,8]$. Staging systems used for VC include the FIGO staging system and the Tumors, Nodes, and Metastases (TNM) Classification system [3,10]. Imaging modalities that can be used for diagnosis and staging include ultrasound, computed tomography (CT), positron emission tomography CT (PET/ $\mathrm{CT}$ ), or Magnetic Resonance Imaging (MRI) [1-3]. MRI is the imaging modality of choice to determine local growth of $\mathrm{VC}$ and also exclude the involvement of adjacent organs [3].

Early-stage VC can be treated with radical local excision with or without inguinofemoral lymph node dissection (LND) [1-4,7-9]. Surgical excision margins are recommended to 
be greater than $1 \mathrm{~cm}$ as studies demonstrate a higher risk of recurrence if surgical margins are less than $8 \mathrm{~mm}[2,3,7,9,10]$. In stage IA, local recurrence (LR) after primary treatment is rare and the risk of LN metastasis is negligible [7-9]. Therefore, inguinofemoral LND is not necessary for stage IA [3,4]. The risk of LN metastasis rises when the depth of invasion is more than $1 \mathrm{~mm}$ which explains the need for LN staging after stage IB $[8,9]$.

SLN is the first draining LN from the primary tumor $[1,2]$. SLN biopsy can be an alternative to LND if there are clinically negative nodes [9]. It can be performed if the tumor measures less than $4 \mathrm{~cm}[1,3,6,7,10]$. If SLN biopsy is negative, no further management is required for nodes $[2,8]$. However, if SLN is positive or not detected, complete inguinofemoral LND is necessary because there is a high risk of disease in other nodes $[1,2,8]$. LND is indicated if the tumor measures $4 \mathrm{~cm}$ or more or if the disease is multifocal $[1,3,6,7,10]$. It is associated with a higher risk of lymphedema when compared to SLN biopsy $[1,3,6,7]$.

The involvement of LNs is the most important prognostic factor for both recurrence and survival [3,6,7,9]. The involvement of pelvic nodes is indicative of metastatic disease $[2,3]$. Treatment involves surgery with RT [1]. Predictors of poor prognosis include metastasis to 2 or more LNs, extracapsular spread, and large metastases $[1,9]$. If radical groin dissection was performed in the presence of one of those mentioned factors, then adjuvant RT can be administered to the groin or pelvis to improve survival [1,2,6-9].

Further imaging with CT or PET/CT might be necessary for patients with locally advanced disease to rule out the involvement of adjacent organs [3]. LN status must be established prior to planning treatment [2]. Locally advanced disease can be treated with radical vulvectomy with bilateral inguinofemoral LND and partial or complete resection of the urethra, vagina, or anus, depending on the extent of their involvement $[4,9]$. Chemoradiation can be offered to patients with locally advanced diseases [4].

Definitive RT, in the form of EBRT or BT, can be offered as primary treatment if surgery is not an option $[2,3,6,9,10]$. The recommended dose of RT is 45-50 Gy in 1.7-2 Gy fractions $[1,2,4,7,8]$. Post-operative RT may be recommended in the case of extracapsular LN spread or metastasis in 1 or more $\mathrm{LN}(\mathrm{s})[3,4,10]$. It can also be considered if surgical margins are less than $8 \mathrm{~mm}$ to reduce risk of recurrence $[4,7]$. Concurrent chemotherapy with cisplatin can be added to primary RT to improve overall outcome $[1,7,10]$.

Systemic chemotherapy can be considered if both surgery and RT are not options for treatment $[3,4,6,9,10]$. Recommended regimens include cisplatin, 5-fluorouracil, and cisplatin or 5- fluorouracil and mitomycin-C [6]. Systemic therapy can be indicated for distant metastasis in addition to local RT to help control the disease [3]. Neoadjuvant chemotherapy is found to reduce the extent of surgery thus helping preserve the function of anal or urethral sphincters $[1,2,7,8,10]$. Palliative chemotherapy can be offered to patients unfit for surgery or RT $[1,4]$.
The aim of surveillance is to detect recurrent disease and determine whether a cure is possible [17]. Follow-up for patients with VC is generally recommended every 3-6 months for the first two years, then every 6-12 months for three more years and annually after that $[1,4-8,10,17]$. This involves a history and exam, cervical screening, counseling, patient education on the symptoms of recurrence, imaging [17]. Recurrence mostly occurs in the first 2 years of follow-up, however about a third of patients develop recurrence 5 years or more later, thus explaining the need for long-term surveillance $[1,3,4,6$ $8,17]$. Patients could either present with local symptoms, such as pruritis or new lesion, or general symptoms, such as leg lymphedema or weight loss [5,17]. Patients who received chemotherapy can undergo CT 10-12 weeks after treatment to determine whether they achieved remission [1]

Distant recurrence can be fatal whereas local recurrence can be salvageable [5,17]. Imaging for distant metastasis might not improve survival. Half of the patients with LR can possibly be cured with surgery, RT with or without chemotherapy [17]. $\mathrm{PET} / \mathrm{CT}$ is indicated prior to pelvic exenteration as a treatment for LR to rule out the possibility of distant metastases $[3,5,10]$ Recurrence in inguinal LNs can indicate a poor prognosis [14 , 7]. Distant metastases can be treated with chemotherapy or palliative RT $[4,7,10]$

Managing patients with VC requires a multi-disciplinary team consisting of a gynecologist, gynecologic oncologist, radiologist and pathologist, among others $[1,3,10]$. Plastic surgeons may also have a role in management with reconstructive surgery, especially after major resection to reduce morbidity [4,7-10]. It is important to consider that these services might not be accessible to all patients. Ismail's Cancer Vulva Management Guidewheel has been designed to be used in an ideal, high-resource setting. Additionally, this guide wheel was designed during the COVID-19 pandemic and does not offer the recommendations established to manage patients in this particular situation.

\section{References}

1. Morrison J, Baldwin P, Buckley L, Cogswell L, Edey K, et al. (2020) British Gynaecological Cancer Society (BGCS) Vulval Cancer Guidelines: Recommendations for Practice. Eur J Obstet Gynecol Reprod Biol 252: 502 525. Link: https://bit.ly/33NrKIS

2. Rogers LJ, Cuello MA (2018) FIGO Cancer Report 2018 Cancer of the vulva. Int J Gynecol Obstet 143: 4-13. Link: https://bit.ly/3KIH61P

3. Nicolić O, Sousa FAE, Cunha TM, Nikolić MB, Otero-García MM, et al. (2021) Vulvar cancer staging: guidelines of the European Society of Urogenital Radiology (ESUR). Insights Imaging 12: 131. Link: https://bit.ly/3nCJtUI

4. Saito T, Tabata T, Ikushima H, Yanai H, Tashiro H, et al. (2018) Japan Society of Gynecologic Oncology guidelines 2015 for the treatment of vulvar cancer and vaginal cancer. Int J Clin Oncol 23: 201-234. Link: https://bit.ly/3A9FZ0G

5. Salani R, Khanna N, Frimer M, Bristow RE, Chen LM, et al. (2017) An update on post-treatment surveillance and diagnosis of recurrence in women with gynecologic malignancies: Society of Gynecologic Oncology (SGO) recommendations. Gynecol Oncol 146: 3-10. Link: https://bit.ly/3tD09x4

6. Koh WJ, Greer BE, Abu-Rustum NR, Campos SM, Cho KR, et al. (2017) Vulvar cancer, version 1.2017, NCCN Clinical practice guidelines in oncology. J Natl Comp Canc Netw 15: 92-120. Link: https://bit.ly/3GDpAEg

Citation: Ismail MS, Ismail F, Ismail J, AlKhalifa M, Ismael R, et al. (2022) Development of a management guidewheel for vulvar cancer. Ann Cytol Pathol 7(1): 001-013. DOI: https://dx.doi.org/10.17352/acp.000024 
7. Francis JA, Eiriksson L, Dean E, Sebastianelli A, Bahoric B, et al. (2019) No 370 - Management of Squamous Cell Cancer of the Vulva. J Obstet Gynaecol Can 41: 89-101. Link: https://bit.ly/3Igj5HW

8. RCOG Publications (2014) Guidelines for the diagnosis and management of vulval carcinoma. Link: https://bit.ly/3AnwxHj

9. Woelber L, Trillsch F, Kock L, Grimm D, Petersen C, et al. (2013) Management of patients with vulvar cancer: a perspective review according to tumour stage. Ther Adv Med Oncol 5: 183-192. Link: https://bit.ly/3KiPT4J

10. Oonk MHM, Planchamp $F$, Baldwin $P$, Bidzinski $M$, Brännström $M$, et al (2017) European Society of Gynaecological Oncology Guidelines for the Management of Patients with Vulvar Cancer. Int J Gynecol Cancer 27: 832837. Link: https://bit.ly/3Kxmxjp

11. Ismail MS (2020) Development of a management guideline wheel for abnormal pap smear and related cervical pathology. Ann Cytol Pathol 5: 013034. Link: https://bit.ly/33MZUpV

12. Ismail MS, Ismail F, Ismail J, Rustogi A, Torsten U, et al. (2020) Development of a management guideline wheel for uterine neoplasms based on different guidelines for management of uterine neoplasms. Cancer Rep Rev 4: 1-27. Link: https://bit.ly/350WPDv

13. Ismail MS. (2019) Flowchart for management abnormal pap smears and related cervical pathology. Applied Colposcopy Cytology 147-158.

14. Ismail MS (2019) Guideline for diagnostic and therapeutic standards in cytology and colposcopy. Applied Colposcopy \& Cytology 197-200.

15. Ismail MS, Hsu S, AlKhalifa MA, Fouad M, Codabux F, et al. (2020) Evaluation of different guidelines for cervical cancer screening and management of abnormal cervical cytology. Ann Cytol Pathol 5: 001-012. Link: https://bit.ly/3qDxmbw

16. Al-Sindi K, Abdulhady K, Ismail MS (2019) Screening of cancer cervix and cervical cytology. Applied Colposcopy \& Cytology 23-32.

17. Elit L, Reade CJ (2015) Recommendations for Follow-up Care for Gynecologic Cancer Survivors. Obstet Gynecol 126: 1207-1214. Link: https://bit.ly/3nCy3Qp 